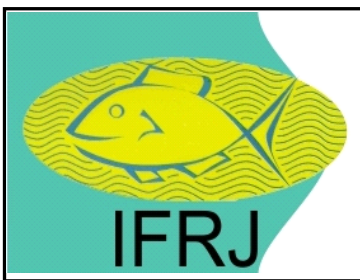

Available online at: http://ejournal-balitbang.kkp.go.id/index.php/ifrj

e-mail:ifrj.puslitbangkan@gmail.com

INDONESIANFISHERIES RESEARCHJOURNAL

Volume 26 Nomor 1 June 2020

p-ISSN: 0853-8980

e-ISSN: 2502-6569

Accreditation Number RISTEKDIKTI: 21/E/KPT/2018

\title{
THE IMPACT OF ENVIRONMENTAL CHANGES ON THE ABUNDANCE OF BLACK MARLIN, Makaira indica (Cuvier, 1832) IN THE EASTERN INDIAN OCEAN
}

\author{
Bram Setyadji ${ }^{\star 1}$ and Zulkarnanen Fahmi ${ }^{1}$ \\ ${ }^{1}$ Research Institute for Tuna Fisheries, Jl. Mertasari No. 140, Sidakarya, Denpasar, Bali-80224, Indonesia \\ Received; September 25-2019 Received in revised from March 13-2020; Accepted March 19-2020
}

\begin{abstract}
Black marlin (Makaira indica) is commonly caught as frozen by-catch from Indonesian tuna longline fleets. Its contribution was estimated around 18\% ( 2,500 tons) from total catch in the Indian Ocean. Catch-per-unit-of-effort (CPUE), as calculated based on commercial catch records, is one of the essential components for running stock assessment. Despite it always being associated with abundance index (number or biomass), little is known on how environmental factors might contribute to it. The objective of the study is to investigate the impact of physical attributes of the ocean on the distribution of black marlin. Data were collected from August 2005 to December 2017 through a scientific observer program (2005-2017) and a national observer program (2016-2017). Most of the monitored vessels were based in Benoa Port, Bali. In general, time trends of abundance fluctuated, although there had been an increasing trend since 2010, then dropped significantly into a relatively similar figure in 2005. Even though Sea Surface Temperature (SST) and Sea Surface Height (SSH) were statistically significant when incorporated into the models, it allegedly wasn't the main driver in determining the abundance of black marlin. Instead, it was more likely driven by spatio-temporal factors (year and area) rather than environmental changes.
\end{abstract}

\section{Keywords: Impact; environmental factors; marlins; INTRODUCTION}

Black marlin (Makaira indica) is an apex predator, highly migratory species (Hill et al., 2016; Williams et al., 2012), and considered as a non-target species of industrial and artisanal fisheries in Indonesian tuna longline fishery (Setyadji \& Nugraha, 2012; Widodo et al., 2016). It ranked second after swordfish in terms of catch composition (Setyadji et al., 2012). It is also known to have high commercial value in the tropical and subtropical Indian and Pacific Ocean (Nakamura, 1985). In the Indian Ocean, it was caught in the area between $20^{\circ} \mathrm{N}$ and $45^{\circ} \mathrm{S}$, but more often off the western coast of India and the Mozambique Channel (IOTCWPB16, 2018).

In the Indian Ocean, black marlin were largely caught by gillnets $(\sim 59 \%)$, followed by longlines $(\sim 19 \%)$, with remaining catches recorded under troll and hand lines (IOTC-WPB16, 2018). Landing Contribution of black marlin from Indonesian fleet (e.g. longline, handline, and gillnet fishery) between 20132017 was around $18 \%$ (IOTC-WPB16, 2018) of total catch in the Indian Ocean, ranked fourth after Iran,
Sri Lanka, and India. The latest stock assessment result, as calculated using Just Another Bayesian Biomass Assessment (JABBA), suggested that black marlin stock of the Indian Ocean is not overfished but subject to overfishing (IOTC-WPB16, 2018). However, the result came with a high degree of uncertainty, which was driven by the increasing catch of offshore gillnet fisheries from I.R. Iran, the combination of gillnet and longline fishery from Sri Lanka, and the presence of deep-freezing longline from Japan and Taiwan off the western coast of India and the Mozambique Channel (IOTC-WPB17, 2019).

Estimations of relative abundance indices enable the use of more detailed models, which could be pivotal in determining the black marlin stock status and its trend. However It is often delivered with some uncertainties, probably due to its over-reliance on spatial (i.e. fishing location), temporal (i.e. year, month, and/or quarter), and operational factors (i.e. length of branchlines, number of hooks between floats), since most of the CPUE analyses are based on the fishery-dependent data, such as logbook. On the other hand, environmental factors are rarely 
involved in the analyses, probably due to poor understanding on the biology of related species, especially on their distribution.

Nevertheless, incorporating environmental factors into the analyses have been attempted by several authors. Sajeevan (2013) investigated the effect of monsoon and lunar cycle toward catch rates of billfish around Andaman and Nicobar Islands. In addition, Rathnasuriya, Gunasekara, Haputhanthri, and Rajapaksha (2016) put sea surface temperature (SST), sea surface chlorophyll (SSC), and dynamic height of the sea surface ( $\mathrm{SSH}$ ) as possible covariates affecting the abundance of billfishes in Sri Lankan waters. Moreover, Wang and Nishida (2013) found that various environmental factors, i.e. Oscillation Index, Dipole Mode Index, Southern Oscillation Index, sheer currents, amplitude of the shear current, thermocline depth, and temperature gradient only contributed around $15-20 \%$ to the nominal CPUE of blue marlin (Makaira mazara) and striped marlin (Tetrapturus audax) in the Indian Ocean. Despite the recent investigations, no attempt has been made on black marlin (M. indica), Indonesian tuna longline fishery in particular.

In this paper, we attempt to investigate the impact of limited environmental variables on the abundance of black marlin, especially from the north eastern Indian Ocean area which are the core fishing ground for Indonesian tuna longline fishery. Results are useful to indicate the relative abundance of black marlin, which is an important fishery resource in the Indian Ocean.

\section{MATERIALS AND METHODS Fishery and Environmental Data}

A total of 2,887 set-by-set data span in detail $1 \times 1$ degree latitude and longitude grid from August 2005 to December 2017 were obtained from Indonesian scientific observer and national observer programs that cover commercial tuna longline vessels, mostly based in Port of Benoa, Bali. Fishing trips usually last from three weeks to three months. Main fishing grounds cover from west to southern part of Indonesian waters, stretching from $75^{\circ} \mathrm{E}$ to $35^{\circ} \mathrm{S}$ (Figure 1). It also informed concerning the number of fish caught by species, total number of hooks, number of hooks between floats (HBF), start time of the set, start time of haul, soak time, and geographic position where the longlines were deployed into the water. The response variable in the models was the catch of black marlin(number of fish). Year and quarter were used as categorical (factor) explanatory variables. Additional information was used as explanatory variables as follows:

a. Area stratification

Area stratification method was applied using GLMtree approach proposed by Ichinokawa \& Brodziak (2010); The algorithm showed that the area divided into four categories (Figure 1).

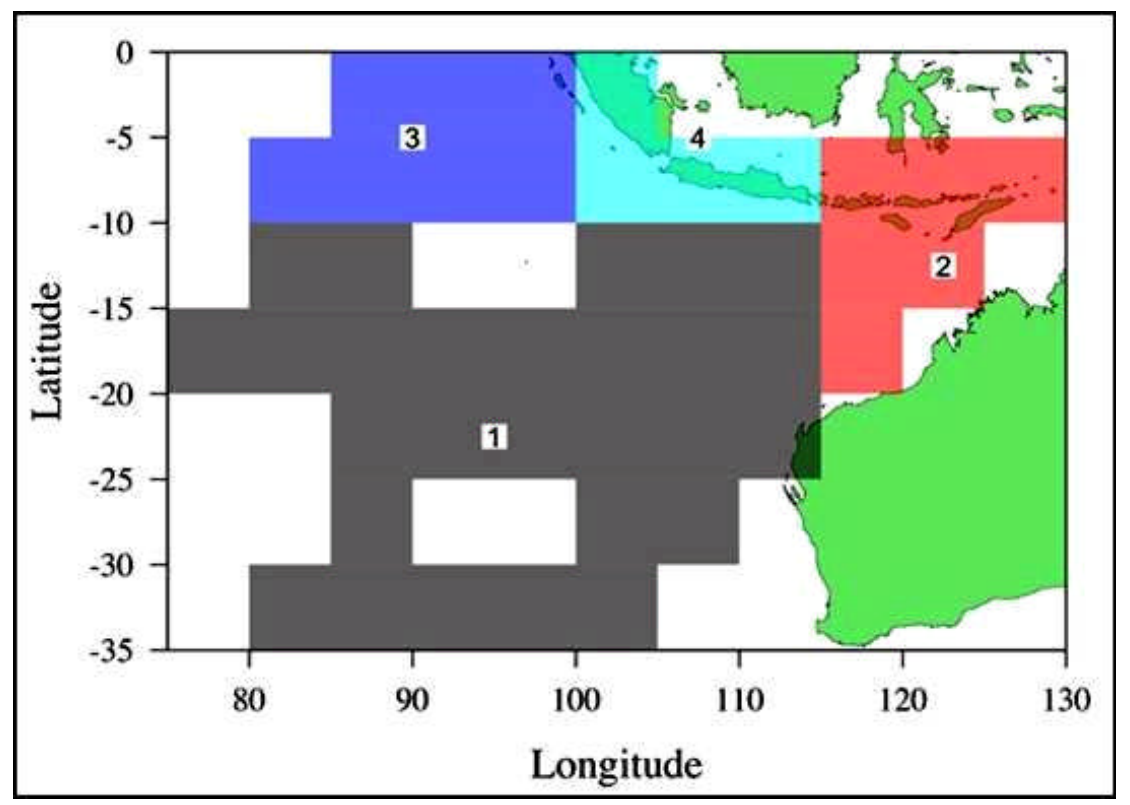

Figure 1. Area stratification used in the analysis based on GLM-tree algorithm.

b. Number of hooks between floats (HBF)

Number of hooks between floats was set as a categorical variable in the model. It was assigned as
1 if $\mathrm{HBF}<10$ hooks (surface longline) and 2 if HBF $\geq 10$ hooks (deep longline) following (Sadiyah et al., 2012); 


\section{c. Soak time}

Soak time was calculated as the time elapsed between the start of the fishing setting and the start of hauling of the longline. Soak time in the model was treated as continuous variable, thus the values were rounded to the nearest integer;

d. Moon phases (29.5 days) were simply categorized into two periods, light and dark, based on Akyol (2013). The light periods consist of the first/last quarters, waxing and waning gibbous, and full moon, while new moon and waning crescent are included into the dark periods.

e. Daily Mean Sea Surface Temperature (SST) was provided by the NOAA/OAR/ESRL PSD, Boulder, Colorado, USA, from their Web site at https:// www.esrl.noaa.gov/psd/. The spatial resolution was a quarter-degree global grid. To address any possibilities of non-linear (quadratic) relationship between CPUE and SST, it was assigned as a quadratic variable (expressed in R as poly (SST, 2)) (Sadiyah et al., 2012) and incorporated as a continuous variable.

f. Daily Mean Sea Surface Height (SSH) was extracted from Copernicus Marine Service Products, namely GLOBAL_REANALYSIS_PHY_001_025 for 20052015 datasets and GLOBAL_ANALYSIS_FORECAST_PHYS_001_015 for 2016-2017 datasets. The spatial resolution was a quarter-degree global grid. To address any possibilities of non-linear (quadratic) relationship between CPUE and $\mathrm{SSH}$, it was assigned as a quadratic variable (expressed in $\mathrm{R}$ as poly ( $\mathrm{SSH}$, 2)) and incorporated as a continuous variable.

\section{Modeling Approach}

We considered four GLM models for investigating the abundance of black marlin in terms of its relation to environmental variables. These models were Poisson without environmental (P1), Poisson with environmental (P2), Negative Binomial without environmental (NB1), and Negative Binomial with environmental (NB2). The configuration of the base model is presented as follows:

$$
\begin{aligned}
\text { Catch }= & \mu+\text { Year }+ \text { Quarter }+ \text { Cat }_{H B F}+\text { Moon } \\
& + \text { SoakTime }+ \text { AreaTree } \\
& + \text { offset }(\log (\text { Hooks })+\varepsilon
\end{aligned}
$$

Catch was defined in the number of black marlin caught, effort was the offset from the natural logarithm of the total number of hooks per set and error distribution followed either Poisson or negative binomial. We used a forward approach to select the explanatory variables and the order they were included in the full model. The first step was to fit simple models with one variable at a time. The variable included in the model with lowest residual deviance was first selected. As the second step, the model with the selected variable then received other variables one at a time, and the model with lowest residual deviance was again selected. This procedure continued until residual deviance did not decrease as new variables were added to the previous selected model. Finally, all main effects and the first order interactions were considered and a backward procedure based on Akaike Information Criterion (AIC) (Akaike, 1974) and Bayesian Information Criterion (BIC) (Schwarz, 1978) were used to select the final models for the six approaches. We also rely on $\mathrm{AIC}$ and $\mathrm{BIC}$ to compare these models.

The qualities of the fittings were assessed by comparing the observed frequency distributions of the number of fishes caught to the predicted frequency distribution, as calculated using the selected models. Kolmogorov-Smirnov test was used to assess if the differences of the two distributions (observed and predicted) were significant. Maps were produced using QGIS version 2.14 (QGIS Developer Team, 2018) and the statistical analyses were carried out using $R$ software version 3.3.3 (R Core Team, 2018), particularly the package pscl (Zeileis et al., 2008), Ismeans (Lenth, 2018), MASS (Venables \& Ripley, 2002), Hmisc (Harrell Jr. et al., 2018), and statmod (Giner \& Smyth, 2016).

\section{RESULTS AND DISCUSSION Results}

\section{Descriptive Catch Statistic}

Scientific observers and national observers recorded catch and operational data at sea following Indonesian tuna longline commercial vessels from 2005-2017 and 2016-2017, respectively. The combined dataset contained 115 trips, 2887 sets, 3499 daysat-sea, and more than 3.5 million hooks deployed, respectively (Table 1 ). The spatial data were distributed mainly in the eastern Indian Ocean with most of the observation conducted in the area of southern Indonesian waters, between $0^{\circ}-35^{\circ} \mathrm{S}$ and $75^{\circ}$ $125^{\circ} \mathrm{E}$. 
Table 1. Summary of observed fishing effort from Indonesian tuna longline fishery during 2005-2017. Results are pooled and also presented by year of observation. Operational parameters are means (upper entries) and standard deviations (lower parenthetical entries).

\begin{tabular}{ccccccccc}
\hline Year & Trips & Sets & Days at Sea & Total Hooks & \multicolumn{2}{c}{ Hooks per Set } & \multicolumn{2}{c}{ Hooks per Float } \\
\hline 2005 & 9 & 108 & 117 & 157,065 & $1,454.31$ & $(151.8)$ & 18.6 & $(1.5)$ \\
2006 & 13 & 401 & 401 & 577,243 & $1,439.51$ & $(214.9)$ & 11.2 & $(3.9)$ \\
2007 & 13 & 265 & 258 & 406,135 & $1,532.58$ & $(326.5)$ & 14.0 & $(4.4)$ \\
2008 & 15 & 370 & 404 & 483,662 & $1,307.19$ & $(385.9)$ & 13.0 & $(4.5)$ \\
2009 & 13 & 283 & 288 & 323,042 & $1,141.49$ & $(234.7)$ & 12.1 & $(4.9)$ \\
2010 & 6 & 165 & 152 & 220,394 & $1,335.72$ & $(457.5)$ & 13.6 & $(5.2)$ \\
2011 & 3 & 105 & 111 & 110,384 & $1,051.28$ & $(173.9)$ & 12.0 & $(0.0)$ \\
2012 & 8 & 198 & 192 & 290,265 & $1,465.98$ & $(559.1)$ & 14.1 & $(2.3)$ \\
2013 & 7 & 225 & 198 & 252,919 & $1,124.08$ & $(210.4)$ & 12.7 & $(2.1)$ \\
2014 & 5 & 167 & 265 & 193,740 & $1,160.12$ & $(176.9)$ & 15.0 & $(2.0)$ \\
2015 & 5 & 148 & 241 & 172,463 & $1,165.29$ & $(145.2)$ & 14.1 & $(3.2)$ \\
2016 & 8 & 244 & 383 & 324,068 & $1,314.89$ & $(146.4)$ & 15.2 & $(6.4)$ \\
2017 & 10 & 218 & 489 & 279,204 & 1.214 .04 & $(395.3)$ & 17.2 & $(4.8)$ \\
\hline
\end{tabular}

\section{CPUE Data Characteristics}

Black Marlin (BLM) nominal CPUE (fish/1000 hooks) series is presented in Figure 2. In general, the catches of BLM during the last decade were highly variable, but showing an increasing trend. The lowest

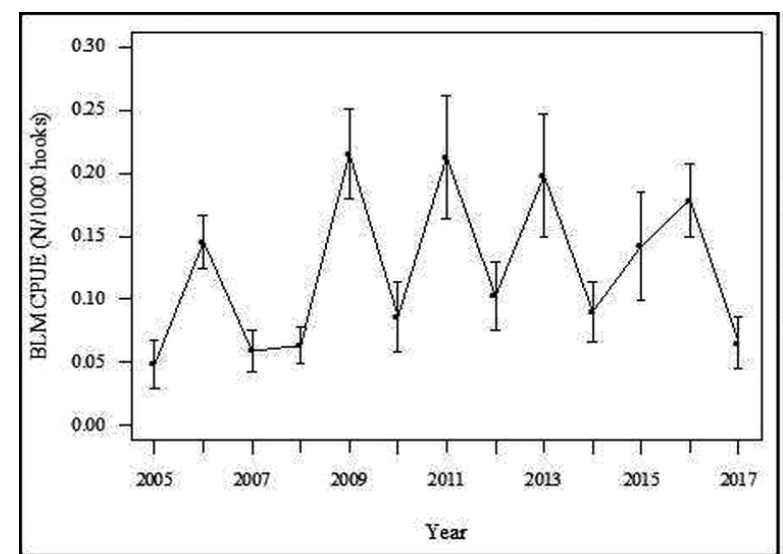

CPUE recorded was in $2005(0.05 \pm 0.19)$, as the highest one was in $2009(0.22 \pm 0.59)$. On the other hand, the proportion of zero catch for BLM was also very high, varying annually between a minimum of $0.82 \pm 0.38$ in 2011 and a maximum of $0.95 \pm 0.23$ in 2017 with an average value of $0.89 \pm 0.30$.

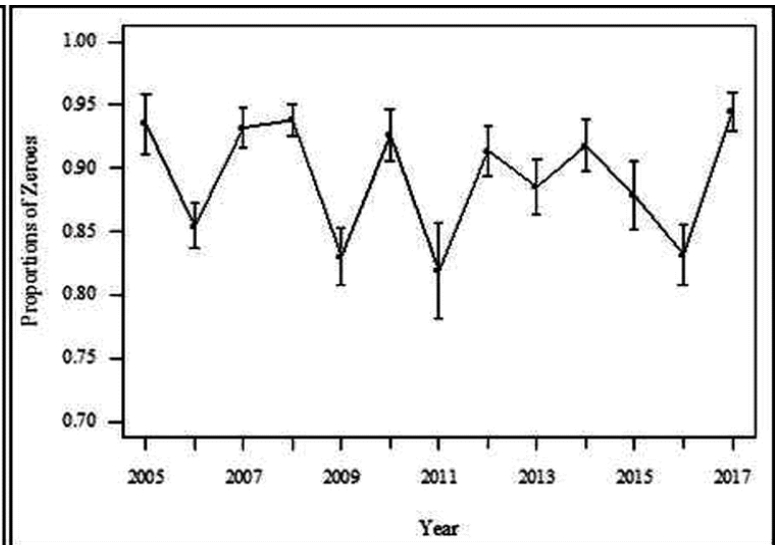

Figure 2. The proportion of zero BLM catches (left panel) and nominal CPUE series (N/1000 hooks) for BLM from 2005 to 2017 (right panel). Remarks: Vertical bars refer to the standard errors.

\section{Influence of SST and SSH}

The number of parameters (k), AIC, BIC, logarithm of the likelihood (logLik), number of predicted zero catches, and $p$ values of Kolmogorov-Smirnov test were calculated using two model structures (Poisson and Negative Binomial) with two different conditions (with or without incorporating environmental factors). The summary is shown in Table 2 . The interactions among variables were excluded to avoid overfitting on the models. A difference of 2 units in the AIC values is not a strong evidence that one model is better than the others (Burnham \& Anderson, 2002). Hence, a simple negative binomial (NB) with incorporating SST and $\mathrm{SSH}$ into the model was preferred as it had the lowestAIC (2343.95) and BIC (2499.11) values (Table 2).
The number of zero catches in the database is 2,575, however, both Poisson and NB models were inaccurate in terms of predicting it, as shown by the differences between the observed and the predicted number of zero catches. Bias of all the models, including the simple ones, were insignificant as indicated by the $p$ values $(>0.05)$.

The negative binomial model with environmental factors was selected as the best profile to describe the effect of environmental changes to the abundance of black marlin. In addition, adding environmental factors only contributed around $2.5 \%-3 \%$ of deviance explained and insufficient to lower the AIC value in all models, although it was considered as influential contributors among variables (Table 3 ). 
Table 2. Summary of indicators as calculated using six model structures: Poisson without environmental (P1), Poisson with environmental (P2), Negative Binomial without environmental (NB1) and Negative Binomial with environmental (NB2). The terms in the column at left indicate: number of parameters (k), Akaike (AIC) and Bayesian (BIC) Information Criteria, logarithm of the likelihood (logLik), number of predicted zero catches (zero), $p$ values as calculated using a Kolmogorov-Smirnov test and deviance explained.

\begin{tabular}{|c|c|c|c|c|c|}
\hline \multirow{2}{*}{ Parameters } & \multicolumn{5}{|c|}{ Model Structures } \\
\hline & P1 & P2 & & NB1 & NB2 \\
\hline $\mathrm{k}$ & 21 & 26 & & 21 & 25 \\
\hline AIC & 2492.75 & 2454.96 & & 2369.46 & 2343.95 \\
\hline $\mathrm{BIC}$ & 2618.08 & 2610.12 & & 2500.76 & 2499.11 \\
\hline logLik & -1225.38 & -1201.48 & & -1162.73 & -1145.97 \\
\hline zero & 2523 & 2520 & & 2538 & 2573 \\
\hline p.value & 0.7371 & 0.6713 & & 0.9717 & 1.0000 \\
\hline Deviance explained & $14.51 \%$ & & $17.03 \%$ & $13.67 \%$ & $16.00 \%$ \\
\hline
\end{tabular}

Table 3. List of deviance table from all models (P1, P2, NB1 and NB2).

1. Model P1

\begin{tabular}{lcccccc}
\hline & Df & Deviance & Residual Df & $\begin{array}{c}\text { Residual } \\
\text { Deviance }\end{array}$ & Pr(>Chi) & \\
\hline NULL & & & 2886 & 2050.3 & & \\
AreaTree & 3 & 184.495 & 2883 & 1865.8 & $2.20 \mathrm{E}-16$ & $* * *$ \\
Year & 12 & 52.501 & 2871 & 1813.3 & $5.05 \mathrm{E}-07$ & $* * *$ \\
Moon2 & 1 & 12.672 & 2870 & 1800.7 & 0.0003712 & $* * *$ \\
Cat_HBF & 1 & 12.607 & 2869 & 1788.1 & 0.0003843 & $* * *$ \\
Quarter & 3 & 17.989 & 2866 & 1770.1 & 0.0004422 & $* * *$ \\
\hline
\end{tabular}

2. Model P2

\begin{tabular}{lcccccc}
\hline & Df & Deviance & Residual Df & Residual Deviance & Pr(>Chi) \\
\hline NULL & & & 2886 & 2050.3 & & \\
AreaTree & 3 & 184.495 & 2883 & 1865.8 & $2.20 \mathrm{E}-16$ & $* * *$ \\
Year & 12 & 52.501 & 2871 & 1813.3 & $5.05 \mathrm{E}-07$ & $* * *$ \\
poly(SSH,2) & 2 & 33.395 & 2869 & 1779.9 & $5.60 \mathrm{E}-08$ & $* * *$ \\
Moon2 & 1 & 13.125 & 2868 & 1766.8 & 0.0002913 & $* * *$ \\
Cat_HBF & 1 & 14.507 & 2867 & 1752.3 & 0.0001397 & $* * *$ \\
Quarter & 3 & 16.732 & 2864 & 1735.6 & 0.0008023 & $* * *$ \\
Soak_Time & 1 & 2.405 & 2863 & 1733.2 & 0.1209584 & \\
poly(SST,2) & 2 & 10.902 & 2861 & 1722.3 & 0.0042915 & $* *$ \\
\hline
\end{tabular}

3. Model NB1

\begin{tabular}{lcccccc}
\hline & Df & Deviance & Residual Df & Residual Deviance & $\operatorname{Pr}(>$ Chi) & \\
\hline NULL & & & 2886 & 1310.0 & & \\
AreaTree & 3 & 127.445 & 2883 & 1182.6 & $2.20 \mathrm{E}-16$ & $* * *$ \\
Year & 12 & 38.775 & 2871 & 1143.8 & 0.0001146 & $* * *$ \\
Moon2 & 1 & 7.648 & 2870 & 1136.2 & 0.0056837 & $* *$ \\
Cat_HBF & 1 & 7.792 & 2869 & 1128.4 & 0.0052485 & $* *$ \\
Quarter & 3 & 8.366 & 2866 & 1120.0 & 0.0390269 & $*$ \\
\hline
\end{tabular}

4. Model NB2

\begin{tabular}{|c|c|c|c|c|c|c|}
\hline & Df & Deviance & Residual Df & Residual Deviance & $\operatorname{Pr}(>\mathrm{Chi})$ & \\
\hline NULL & & & 2886 & 1344.7 & & \\
\hline AreaTree & 3 & 130.971 & 2883 & 1213.8 & $2.20 \mathrm{E}-16$ & *** \\
\hline Year & 12 & 39.559 & 2871 & 1174.2 & $8.51 \mathrm{E}-05$ & $* * *$ \\
\hline poly $(\mathrm{SSH}, 2)$ & 2 & 28.12 & 2869 & 1146.1 & 7.83E-07 & $\star \star * *$ \\
\hline Moon2 & 1 & 6.647 & 2868 & 1139.4 & 0.00993 & ** \\
\hline Cat_HBF & 1 & 8.224 & 2867 & 1131.2 & 0.004134 & ** \\
\hline Quarter & 3 & 7.599 & 2864 & 1123.6 & 0.055065 & \\
\hline poly $(S S T, 2)$ & 2 & 7.925 & 2862 & 1115.7 & 0.019017 & * \\
\hline
\end{tabular}


The estimation of standardized catch rates is shown in Figure 3. Overall, the time trends of standardized CPUE were highly fluctuated although there was an indication of increasing trend since 2010, but then dropped significantly in 2017 into relatively similar level as in 2005.

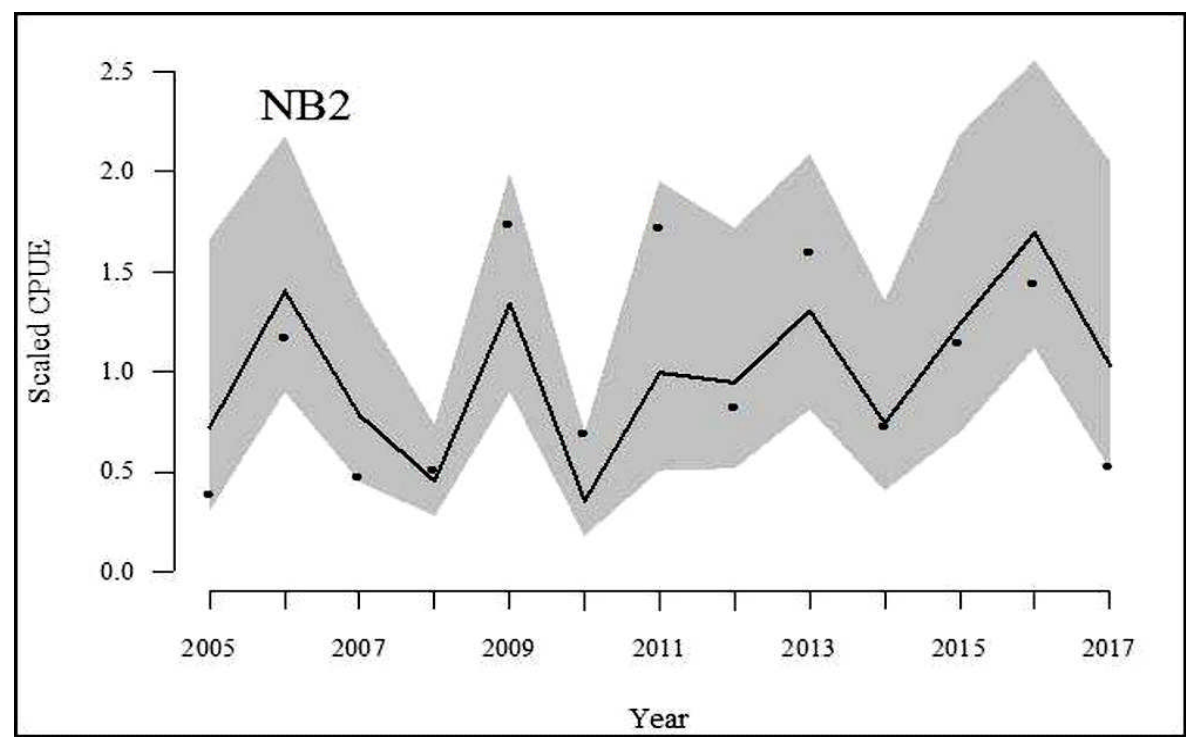

Figure 3. Standardized catch per unit effort (CPUE) calculated using Negative Binomial with environmental factors (NB2). Values were scaled by dividing them by their means.

In addition, the level of uncertainty (showed by the large range of confidence intervals) must be closely put into consideration, even though SST and SSH were significantly contributedlt looked like the abundances of black marlin were driven by other factors, such as the presence of large sum zero-catchper-set in the data, rather than environmental factors. The lack of spatial coverage also hampered the calculation and perhaps inflicted some biases.

\section{Discussions}

Based on the previous study, the model was allegedly influenced more by the number of zero-catchper-set instead of spatio-temporal factors (Setyadji et al., 2018). Moreover, lack of spatial coverage and the fact that black marlin is not a target species hamper the calculation. A few workarounds can be done in order to reduce unwanted zero catches, i.e., using core area (Yokoi et al., 2016). This area, which is a $1 \times 1$ degree-based catch block with a minimum constant catch for at least 6 years (doesn't need to be consecutive), could reduce the proportion of zero catch from $93 \%$ to $58 \%$. Other solutions, such as incorporating random effect into General Linear Mixed Model (GLMM) (ljima, 2017), using more complex model, i.e., delta-lognormal (Wang, 2017), or applying to smooth in the zero-inflated negative binomial model (Minami et al., 2007), could be considered.
However, unlike tunas, which are usually forming school, billfishes (i.e. marlins and swordfish) prefer to get together within specific oceanographic features such as temperature fronts (Brill \& Lutcavage, 2001). It is likely due to their life characteristics, where they usually live scarcely and solitary, despite being at the larval or adult stage (Au, 1998; West, 2004). Therefore, it is difficult to estimate their abundance just by merely limited catch and effort data from just a single gear (i.e. longline). In order to get a better understanding amid the "true abundance" of billfishes, we put some environmental factors as additional covariates into the model.

Both sea surface temperature (SST) and sea surface height (SSH) are closely related to the abundance of tuna and billfish species (Lan et al., 2017; Lumban-Gaol et al., 2015; Su et al., 2011, 2015). In this study, high CPUE occurred between $29-31^{\circ} \mathrm{C}$, wherein CPUE propensity linearly rose with SSH. Overall, SST was considered as the best predictor for determining the spatial distribution for most marlin species (Su et al., 2011, 2015), although there was a weak relationship between SST and SSH. Even though SST played an important role in this study, it actually did not explain the model a lot. In fact, it only explained merely just $3.4 \%$ of total residual deviance in model NB2. Instead, AreaTree, Year, and SSH were the main predictors, contributing $57.2 \%$, $17.3 \%$, and $12.3 \%$, respectively. 


\section{CONCLUSION}

Despite some constraints related to the data quality (spatial coverage), in general Sea Surface Temperature (SST) and Sea Surface Height (SSH) were statistically significant when incorporated into the models, but it allegedly wasn't the main driver in determining the abundance of black marlin. Instead, it was more likely driven by the effects of spatiotemporal factors (year and area).

\section{ACKNOWLEDGMENT}

All authors contributed equally to this work. All authors discussed the results and implications and commented on the manuscript at all stages. We would like to thank all scientific observers of the Research Institute for Tuna Fisheries (RITF) and national observers of Directorate General of Capture Fisheries (DGCF) for their contribution in collecting data throughout the years. We also would like to extend our gratitude to various organizations, namely, Commonwealth Scientific and Industrial Research Organization (CSIRO), the Australian Centre for International Agricultural Research (ACIAR), and the Research Institute for Capture Fisheries (RCCF) for their funding support through research collaboration in the project FIS/2002/074: Capacity Development to Monitor, Analyze and Report on Indonesian Tuna Fisheries. The authors would also like to thank Dr. Humber Andrade, Dr. Rui Coelho, and Dr. Sheng-Ping Wang for their valuable inputs in developing the analyses.

\section{REFERENCES}

Akaike, H. (1974). A new look at the statistical model identification. IEEE Transactions on Automatic Control, 19(6), 716-723. https://doi.org/10.1109/ TAC.1974.1100705.

Akyol, O. (2013). The influence of the moon phase on the CPUEs of swordfish gillnet fishery in the Aegean Sea, Turkey. Turkish Journal of Fisheries and Aquatic Sciences, 13(2), 355-358. https:// doi.org/10.4194/1303-2712-v13_2_18.

Au, D. W. (1998). Protecting the reproductive value of swordfish, Xiphias gladius, and other billfishes. In: Barrett, Isadore, Oscar Sosa-Nishizaki, and Norman Bartoo (Eds.). Biology and Fisheries of Swordfish, Xiphias Gladius, 142, 219-226.

Brill, R. W., \& Lutcavage, M. E. (2001). Understanding environmental influences on movements and depth distributions of tunas and billfishes can significantly improve population assessments. American Fisheries Society Symposium, 25, 179-198.

Burnham, K. P., \& Anderson, D. R. (2002). Model selection and multimodel inference: $A$ practical information-theoretic approach (2nd ed). Springer.

Giner, G., \& Smyth, G. K. (2016). statmod: Probability calculations for the inverse Gaussian distribution. ArXiv Preprint ArXiv:1603.06687.

Harrell, Jr., F. E., Dupont, C., \& Others. (2018). Hmisc: Harrell Miscellaneous. https://CRAN.Rproject.org $/$ package $=\mathrm{Hmisc}$

Hill, N. J., Tobin, A. J., Reside, A. E., Pepperell, J. G., \& Bridge, T. C. (2016). Dynamic habitat suitability modelling reveals rapid poleward distribution shift in a mobile apex predator. Global Change Biology, 22(3), 1086-1096. http:// dx.doi.org/10.1111/gcb.13129.

Ichinokawa, M., \& Brodziak, J. (2010). Using adaptive area stratification to standardize catch rates with application to North Pacific swordfish (Xiphias gladius). Fisheries Research, 106(3), 249-260. https://doi.org/10.1016/j.fishres.2010.08.001.

ljima, H. (2017). CPUE standardization of the Indian Ocean swordfish (Xiphias gladius) by Japanese longline fisheries: Using negative binomial GLMM and zero inflated negative binomial GLMM to consider vessel effect. Paper Presented on 15th Working Party on Billfish, San Sebastian, Spain, 10-14 September 2017, IOTC-2017-WPB15, 32.

IOTC-WPB16. (2018). Report of the 16th Session of the IOTC Working Party on Billfish (Working Party Report IOTC-2018-WPB16-R[E]; p. 97). Indian Ocean tuna Commission (IOTC). http://iotc.org/ sites/default/files/documents/2018/11/IOTC-2018WPB16-RE_FINAL_-_DO_NOT_MODIFY.pdf

IOTC-WPB17. (2019). Report of the 17th Session of the IOTC Working Party on Billfish (Working Party Report IOTC-2019-WPB17-R[E]; p. 92). Indian Ocean tuna Commission (IOTC). https://iotc.org/ sites/default/files/documents/2019/10/IOTC-2019WPB17-RE_-_FINAL.pdf

Lan, K.-W., Shimada, T., Lee, M.-A., Su, N.-J., \& Chang, Y. (2017). Using remote-sensing environmental and fishery data to map potential yellowfin tuna habitats in the tropical Pacific Ocean. Remote Sensing, 9(5), 444. https:// doi.org/10.3390/rs9050444. 
Lenth, R. (2018). emmeans: Estimated Marginal Means, aka Least-Squares Means. https:// CRAN.R-project.org/package=emmeans.

Lumban-Gaol, J., Leben, R. R., Vignudelli, S., Mahapatra, K., Okada, Y., Nababan, B., Mei-Ling, M., Amri, K., Arhatin, R. E., \& Syahdan, M. (2015). Variability of satellite-derived sea surface height anomaly, and its relationship with Bigeye tuna (Thunnus obesus) catch in the Eastern Indian Ocean. European Journal of Remote Sensing, 48(1), 465-477. https://doi.org/10.5721/ EuJRS20154826.

Minami, M., Lennert-Cody, C. E., Gao, W., \& RomanVerdesoto, M. (2007). Modeling shark bycatch: The zero-inflated negative binomial regression model with smoothing. Fisheries Research, 84(2), 210-221. https://doi.org/10.1016/ j.fishres.2006.10.019.

Nakamura, I. (1985). Billfishes of the world. An annotated and illustrated catalogue of marlins, sailfishes, spearfishes and swordfishes known to date. FAO Species Catalogue; FAO Fisheries Synopsis, 5(125), 65.

QGIS Developer Team. (2018). QGIS Geographic Information System. Open Source Geospatial Foundation Project. http://qgis.osgeo.org/

R. Core Team. (2018). R: A Language and Environment for Statistical Computing. $\mathrm{R}$ Foundation for Statistical Computing. https:// www.R-project.org/

Rathnasuriya, M. I. G., Gunasekara, S. S., Haputhanthri, S. S. K., \& Rajapaksha, J. K. (2016). Environmental preferences of Billfish in Bay of Bengal: A case study in longline fishery of Sri Lanka. Paper Presented at 14th Working Party on Billfish, Victoria, Seychelles, 6-10 September 2016. IOTC-WPB14-2016-10 Rev1, 18.

Sadiyah, L., Dowling, N., \& Prisantoso, B. I. (2012). Developing recommendations for undertaking CPUE standardisation using observer program data. Ind.Fish.Res.J, 18(1), 19-33. https:// doi.org/10.15578/ifrj.18.1.2012.19-33

Sajeevan, M. K. (2013). Evaluation of the effect of lunar cycle, monsoon and spatial differences on billfishes. Paper Presented at 11th Working Party on Billfish, La Reunion, France, 18-22 September 2013. IOTC-2013-WPB11-20, 17.
Schwarz, G. (1978). Estimating the dimension of a model. The Annals of Statistics, 6(2), 461-464.

Setyadji, B., Andrade, H. A., \& Proctor, C. H. (2018). Standardization of Catch Per Unit Effort with High Proportion of Zero Catches: An Application to Black Marlin Istiompax indica (Cuvier, 1832) Caught by The Indonesian Tuna Longline Fleet in The Eastern Indian Ocean. Turkish Journal of Fisheries and Aquatic Sciences, 19(2), 119-129. https://doi.org/10.4194/1303-2712-v19_2_04

Setyadji, B., Jumariadi, J., \& Nugraha, B. (2012). Catch estimation and size distribution of billfishes landed in Port of Benoa, Bali. Indonesian Fisheries Research Journal, 18(1), 35-40. https:/ /doi.org/10.15578/ifrj.18.1.2012.35-40

Setyadji, B., \& Nugraha, B. (2012). Hasil tangkap sampingan (HTS) kapal rawai tuna di Samudera Hindia yang berbasis di Benoa. J. Lit. Perikan. Ind, 18(1), 43-51. http://dx.doi.org/10.15578/ jppi.18.1.2012.43-51.

Su, N.-J., Sun, C.-L., Punt, A. E., Yeh, S.-Z., \& DiNardo, G. (2011). Modelling the impacts of environmental variation on the distribution of blue marlin, Makaira nigricans, in the Pacific Ocean. ICES Journal of Marine Science, 68(6), 10721080. https://doi.org/10.1093/icesjms/fsr028.

Su, N.-J., Sun, C.-L., Punt, A. E., Yeh, S.-Z., \& DiNardo, G. (2015). Environmental influences on seasonal movement patterns and regional fidelity of striped marlin Kajikia audax in the Pacific Ocean. Fisheries Research, 166, 59-66. https:// doi.org/10.1016/j.fishres.2014.07.017.

Venables, W. N., \& Ripley, B. D. (2002). Modern Applied Statistics with S (Fourth). Springer. http:/ /www.stats.ox.ac.uk/pub/MASS4

Wang, S.-P. (2017). CPUE standardization of swordfish (Xiphias gladius) caught by Taiwanese longline fishery in the Indian Ocean. Paper Presented on 15th Working Party on Billfish, San Sebastian, Spain, 10-14 September 2017, IOTC2017-WPB15-17, 28.

Wang, S.-P., \& Nishida, T. (2013). Correlations between environmental factors and CPUEs of blue marlin (Makaira mazara) and striped marlin (Kajikia audax) caught by Taiwanese longline fishery in the Indian Ocean. Paper Presented at 11th Working Party on Billfish, La Reunion, 
France, 18-22 September 2013. IOTC-2013WPB11-22 Rev_2, 14.

West, A. P. (2004). Aspects of the early life history of billfish off Kona, Hawaii [PhD Thesis].

Widodo, A. A., Prisantoso, B. I., \& Suprapto, S. (2016). Perikanan pancing ulur di Samudera Hindia: Hasil tangkapan ikan berparuh yang di daratkan di Sendang Biru, Malang, Jawa Timur. J.Llit.Perikan.Ind, 18(3), 167-173. https://doi.org/ 10.15578/jppi.18.3.2012.167-173.

Williams, A. J., Farley, J. H., Hoyle, S. D., Davies, C. R., \& Nicol, S. J. (2012). Spatial and sexspecific variation in growth of albacore tuna (Thunnus alalunga) across the South Pacific Ocean. PloS One, 7(6), e39318. https://doi.org/ 10.1371/journal.pone.0039318.
Yokoi, H., Semba, S., Satoh, K., \& Tsutomu, N. (2016). Standardization of catch rate for black marlin (Istiompax indica) exploited by the Japanese tuna longline fisheries in the Indian Ocean (1971-2015). Paper Presented on 14th Working Party on Billfish, Victoria, Seychelles, 6-10 September 2016, IOTC-2016-WPB1419_Rev1,17.

Zeileis, A., Kleiber, C., \& Jackman, S. (2008). Regression models for count data in $\mathrm{R}$. Journal of Statistical Software, 27(8), 1-25. https:// doi.org/10.18637/jss.v027.i08. 